\title{
Community Modelling: A technique for enhancing local capacity to engage with flood risk management
}

Dr Catharina Landström

School of Geography and the Environment, University of Oxford, South Parks Road, Oxford OX1 3QY, UK, catharina.landstrom@ouce.ox.ac.uk

Corresponding author

Miss Matilda Becker

School of Geography and the Environment, University of Oxford, South Parks Road, Oxford OX1 3QY, UK, matilda.becker@ouce.ox.ac.uk

Dr Nicholas Odoni

Department of Geography, University of Durham, Lower Mountjoy, South Road, Durham, DH1 3LE, UK, nicholas.a.odoni@durham.ac.uk

Professor Sarah J Whatmore

School of Geography and the Environment, University of Oxford, South Parks Road, Oxford OX13QY, UK, sarah.whatmore@ouce.ox.ac.uk

\section{Abstract:}

Widening acceptance of the value of public participation in local flood risk management (FRM) brings new challenges. A key issue is the capacity of local communities to participate in expert-led FRM. Community Modelling (CM) is a technique developed to enhance local ability to engage with water management. Drawing on participatory research in geography and science studies the technique has four core elements: resource minimalism, strategic participant recruitment, standardised software and actively making connections with decision makers. We introduce CM and illustrate it with a case study of local FRM in England. In the example case free computer software, known amongst technical experts, was used to coproduce representations of local flooding problem with a small group affected residents. Guided by a natural science modeller the group examined the causes of local flooding and considered possible mitigation measures. Social science expertise facilitated interaction with local flood risk managers, technical experts and decision making authorities.

Keywords: participation, local community, flood risk management, computer modelling

Funding: This work was supported by the Economic and Social Science Research Council Impact Acceleration Award 1602-KEA-200. 


\section{Introduction}

Public participation is increasingly viewed as desirable in flood risk management (FRM) and it is explicitly required in the European Floods Directive (EU, 2007). However, there are many challenges to the effective involvement of local communities. The need to include local actors beyond the already engaged stakeholders has been extensively discussed and the challenge of avoiding the reproduction of existing social inequalities has been highlighted (c.f. Evers, 2012). Studies have also shown that the reliance on scientific and technical expertise in FRM presents a barrier to local participation and excludes local lay knowledge from institutional decision making. Maynard (2013) shows that geographical scaling and different decision making levels mitigate against the uptake of local knowledge in water management. Water managers find it difficult to use contributions other than technical expert knowledge beyond the river reach scale, attempts to involve publics and stakeholders on sub-catchment, catchment and larger scales often fail. In a study of participatory FRM in England Thalers and Levin-Keitel (2016) found that local involvement requires a range of resources, critical amongst them knowledge, money and time. The knowledge needed to engage meaningfully is often unevenly distributed which prevents effective public participation (c.f. Newig et al 2014). This paper addresses the access to science-based knowledge in FRM.

Efforts to strengthen and promote local participation in FRM have focused on more inclusive decision making processes (c.f. Evers 2012). Our approach to the same objective is to increase local capacity to participate by widening access to the computer modelling tools used in decision making processes. Community Modelling (CM) is a technique that makes science- 
based computer modelling tools useable and useful to local communities, thereby increasing their ability to participate in expert-led FRM.

Computer modelling is an established approach in participatory environmental science. Used to address issues in FRM Participatory Modelling (PM) integrates social and natural elements in computer-based representations and analysis. Most PM projects invite lay participants for consultation and feedback to improve model quality and model application (Voinov and Bousquet, 2010). Participants are asked to provide data, or opinions regarding the accuracy of the model representation of the behaviour of a local system. Projects also use PM to support stakeholders' understanding of the environmental system, intending to improve management and communication between stakeholders. Case studies show that PM can generate models that work as communication tools, bridging the divide between stakeholders and decision makers, by rendering ideas and perspectives in a format which both parties can understand. However, Voinov and Bousquet (2010) find that PM projects tend to be initiated and driven by scientists and scientific interests, even when the ambition is to support local communities. Voinov et al. (2016) discern a shift in focus, PM projects are becoming more aware of the social dynamics of the modelling process, but there were no change regarding funding, initiation and aims. PM projects remain resource demanding scientific undertakings with the key aim to generate new scientific models, now including social elements.

The challenges of making PM research impact on FRM practice is noted by Evers et al. (2016) in a presentation of a new approach called 'collaborative modelling', underpinned by a sophisticated social science understanding of participation. Applying a social learning framework Evers et al. developed a 'collaborative platform' to support a process with four stages: technical, choice of scenarios, simulation of scenarios and discussion of simulation 
results. Despite the success of their participatory modelling and the social learning process, the FRM initiative within which their work was undertaken 'did not proceed further with the concrete implementation of the EU floods directive, in part due to the short participation process' (Evers et al., 2016: 343). It is common for public participation in scientific research not to translate into participatory FRM. Henly-Shepard et al (2015) address this more generally, pointing out that PM tend to have a relatively low number of activities attended by the lay participants, despite projects running for several years. The discussion in Evers et al. (2016) confirms this, noting that after discussing modelling results there was nothing more to do for the local participants in the research project.

Lack of uptake of PM in FRM has multiple causes, one being that scientific projects tend to produce models for which there is limited demand. Hare (2011) argues that the assumption, common among scientists, that project outputs will be used to support decision making because local stakeholder views are represented in the modelling outcome, is mistaken. The literature indicates that flood risk - and other environmental - managers view participation differently from what PM offers. Reed (2008) explains that the most important aspect of participatory management is the process, but scientific PM projects focus on knowledge outputs and new models, despite aiming to impact on FRM. That PM adheres to the format of scientific projects brings with it the same problems of uptake amongst environmental decision makers and managers as non-participatory modelling. Studies have shown that scientists want to create new models while managers and decision makers need models that are maintained and well documented. Webler et al. (2011) show how water quality scientists and managers distinguish between models that are useful in science and in policy making. Also, the ability of water managers to adopt new approaches depends on interest, resources and regulatory frameworks 
(Hare, 2011). In addition local decision makers have been found not to use models as they lack the time.

Shifting the emphasis from modelling to participation as the main objective requires thinking beyond the research project. The objective then becomes to increase the capacity of local communities to engage with the FRM process independently of the project scientists. The research project must be viewed as the beginning of the process, not as a self-contained exercise that ends with the delivery of knowledge outputs. The difference such a change in perspective makes is demonstrated in a case study by Whitman et al. (2015) that brings a Participatory Action Research (PAR) approach to PM. This research project was intended as an intervention to change environmental management practices. They used maps and models to coproduce knowledge with members of a local environmental NGO, involved with integrated catchment management. Over three months the small transdisciplinary group coproduced new mapping and modelling tools that could be used by that NGO (and similar organisations), to address the problem (farm slurry) in other locations in the future.

The Community Modelling (CM) technique introduced below and illustrated with a case study of FRM in Otley, UK, follows the same trajectory as the PAR modelling discussed by Whitman et al. (2015). The objective is to increase the local community's capacity to engage with environmental risk management in the long-term by using computer models. Building on previous participatory environmental research and critical social science analysis the CM technique has four core elements: resource minimalism, strategic participant recruitment, standardised software and making connections with decision makers. In the following sections we outline the principles of CM, explain how it builds on previous approaches and present a case-study of its application to FRM in the town of Otley in North Yorkshire. 


\section{The principles of Community Modelling}

Community Modelling (CM) is intended for use in any area of environmental management in which computer models play a role. The technique uses scientific computer modelling to increase the ability of local communities to participate in the governance of environmental problems in their locality. The objective to increase local capacity to participate distinguishes CM from the PM projects described in the literature which aim to produce new scientific knowledge and new computer models. In the process leading to increased local capacity to participate CM projects collaboratively generate computer model representations relevant to local matters of concern.

A CM project should be short - take between six and eight months including preparation and reporting time. The participatory activities comprise three to four sessions over a three to fourmonth period. Two academics (a 'facilitator' with social science expertise and a natural science 'modeller') lead the activities. The academics organise and facilitate the participatory modelling sessions, they also undertake initial preparations, 'backstage' activities supporting the sessions, and follow-up writing, to ensure the success of the local engagement.

CM resembles the PAR approach of Whitman et al. (2015) but it originates in the Environmental Competency Groups (ECGs) methodology which is underpinned by poststructuralist, more-than-human philosophical notions (Whatmore, 2009). This means, among other things, emphasising the role of objects in the process and thinking of expertise as a distributed achievement. The ECGs methodology has had demonstrated success, enabling the combination of local and scientific knowledge to improve local FRM in the town of Pickering, 
Yorkshire (Lane et al., 2011; Whatmore and Landström, 2011). Differently from the research focussed ECGs, CM is a technique that can be deployed in response to local requests and that delivers a bespoke computer model supporting local people in engaging with expert bodies and decision making authorities in the locality.

Informed by participatory approaches in geography and cognate disciplines CM differs from the natural science-led PM as described in the literature by the four core elements: resource minimalism, strategic participant recruitment, standardised software and making connections with decision makers.

\subsection{Resource minimalism}

Community Modelling projects are set up in the locality with the environmental problem and run by two people with expertise in social science and natural science modelling respectively. Comprising three to four meetings over a three to four-month period, they have a very similar time and staffing scope to the PAR modelling (Whitman et al., 2015). The rationale is the same: to make it possible for local communities, e.g. city councils, to cover the costs of expert assistance. In addition the relatively short time makes it easier for local participants to attend all sessions. In contrast, scientific PM projects described in the literature, take longer, often a year or more, and involve larger teams of academics. The time and number of academics involved restricts the initiative of PM to research institutions and directs the efforts towards generating outcomes useful to scientists. That CM aims to put existing scientific knowledge and tools to use in ways that take local people's knowledge into account makes it possible for one natural scientist to lead the participatory modelling. Projects aiming to create new scientific knowledge and models require more scientists and longer time. 


\subsection{Strategic participant recruitment}

A Community Modelling project begins with a qualitative social science mapping of the community affected by an environmental problem. This provides an understanding of the social dynamics and power relations shaping the articulation of local environmental matters of concern. The mapping includes the identification of potential local participants for the modelling group. The aim is to engage a small number (four to eight) local participants who are selected based on their interest, suitability and potential for long-term commitment (as demonstrated by past involvement). The recruitment process involves individual interviews with potential participants by the social scientist, to clarify expectations on behalf of both parties. The interviews also establish that participants can attend all the scheduled sessions and that they have a commitment to future involvement with the local management of the environmental problem.

The selection of participants for CM is based on the ECGs methodology (Whatmore, 2009) and it differs from the PM projects reported in the literature in that it appreciates self-selection and participants with a previous interest in the topic. Focussing on what participants will do after the end of the project CM does not ask standard questions about whether participants are invited or self-selected, whether participants come from recognised organisations or the 'general' public (Voinov et al., 2016). The identification of potential CM participants also contrasts with social science-based approaches such as iterative top-down stakeholder identification methodology’ aiming to ‘minimise sampling bias’ (Maskrey et al., 2016: 280). In addition, CM involves small groups, four to eight local participants, while PM projects work with much larger groups, for example, Maskrey and collaborators selected 40 participants 
'representing a wide range of situated knowledge and expertise including certified experts from context setting and key player organisations, and uncertified experts from local community and campaigning groups’' (Maskrey et al., 2016: 280).

The CM approach to participant selection is intended to be 'strategic'. The aim is to involve people who have the potential to involve other local residents and to continue to engage with the local environmental management process after the project has ended. This resonates with Evers et al. (2016) identification of 'local champions' as distinct from 'primary', 'secondary' and 'tertiary' stakeholders, all with different positions in relation to local flood risk management, hence, playing different roles in the participatory modelling process. CM projects recruits existing or potential local champions in a way that also align with Whitman et al., (2015) who worked with members of a local NGO. Local participants who are members of environmental groups usually have practical experience of environmental processes and are committed to enduring engagement. Local environmental groups can also make the model and the knowledge generated with it, available to interested local people after the end of the project, supporting ongoing public engagement. Participants involved with local environmental groups also have access to the knowledge resources generated by such groups, which can add to the quality of the modelling.

Scientific PM often seeks to represent decision making in the models and thus treats local participants also as subjects to be researched in the participatory process. In contrast, CM considers local participants in the modelling sessions to be partners who take responsibility for conveying the knowledge gained and the results to the wider local public. The role of local participants in the CM sessions is initially to decide what to represent in the computer model and which questions to address with the model. During this process they also contribute 
knowledge about the local environmental matter of concern and learn about how computer modelling, central in environmental management, works. In the second and third CM sessions they take part in hands-on modelling of the local problem.

\subsection{Standardised modelling software}

Differently from PM projects with scientific objectives CM uses 'off-the-shelf' modelling software that is established and known among the technical experts in the relevant field. It is critical to use standardised software in free-to-use versions to make sure that the local community can take possession of the model representation of the locality and the environmental process investigated. Proprietary software often requires significant licensing fees that would make it impossible for a local community to continue to use a model after the end of a project. It is also critical to use software that adheres to the standards used by the technical experts who advise decision makers. Use of standard modelling software makes project outcomes transparent to experts and it can make it possible to couple the detailed local models set up in CM projects with larger scale models used by technical consultants.

One of the tasks of the natural scientist in CM is to find out which modelling approaches the technical experts in the relevant field use. It is important to note that the goal is not to make the lay participants able to use the model in the same way as a scientific modeller would. CM aims for the lay participants to develop an understanding of how modelling works, how the environmental processes they experience are represented in models and how model outputs can be used to consider possible local problem mitigation options. 
The use of ready-made software is a strategy shared with the PAR approach (Whitman et al., 2015) and it sets the two apart from PM in general. All the PM projects overviewed in Voinov and Bousquet (2011) and Voinov et al. (2016) created new software, using various mathematical approaches, often aiming to represent social dimensions, i.e. decision making, in the model. Even PM projects emphasising social learning (Van der Wal et al., 2016) or that address decision making (Becu et al., 2008; Smith et al., 2016) aim to create new software.

\subsection{Making connections}

Running a Community Modelling project involves actively connecting the modelling group with local environmental decision makers. The social scientist initiates this connection, using the social science mapping of the local decision making landscape and environmental matter of concern, undertaken before the modelling commenced. When the modelling group starts the social scientist and the modeller make contact with local environmental managers, technical experts and decision makers to arrange for them to meet with the local participants.

We have found no accounts of this kind of active connection of local project participants with local decision makers in the PM literature, despite the widespread recognition that uptake of knowledge produced in participatory projects presents a major challenge. Some barriers to uptake of local participatory research outputs arise from the routines of environmental management processes. Van Ast and Gerrits (2017) found that the involvement of technical experts in the decision making process marginalises contributions made through public participation. The reluctance of environmental managers to adopt new ways of working and new knowledge coming from non-experts has been documented for decades (cf. Petts and Brooks, 2006). With regard to PM Hare (2011: 396) remarks that uptake may be hampered by 
the fact that participatory processes that 'shift power and responsibility in decision-making are not seen as a priority within the organisation'.

Overcoming the obstacles to effective uptake of coproduced knowledge and long-term local engagement requires considered action. Community Modelling draws on a critical social science perspective on expert-led environmental management to address this challenge. Critical in this is to arrange face-to-face meetings of local residents participating in the project and relevant decision makers, to support better uptake of local knowledge in the formal environmental management process.

In the next section, we present an example of Community Modelling used to address flooding in a badly affected area of the town centre in Otley, a rural town formally part of the city of Leeds in the north of England. We begin with an overview of the project and then we discuss the key features of CM in this particular project.

\section{Community Modelling addressing flood risk in Otley}

Nestled in the valley of the River Wharfe Otley has a history of floods appearing and disappearing within a matter of hours. Evidence of the extent and damage of flooding in the town has been recorded for the last 100 years. The responsibility for FRM in Otley lays with Leeds City Council in collaboration with the Environment Agency (EA), a national expert advisory and regulatory body. The CM project in Otley was initiated by a member of the Otley Town Council (not an FRM authority), who approached Oxford University wanting to explore flood processes in the town. This led to collaboration on a funding bid within a knowledge exchange programme. When funded the project was run over six months, including planning, 
preparations and reporting (Fig. 1). The academic team comprised two project leads based in Oxford, and one social and one natural scientist working in the locality as CM facilitator and modeller, respectively.

Over four sessions the Community Modelling group (comprising the facilitator, the modeller and local residents) learned about both modelling and flooding (Fig. 2). In the first session the group collectively decided what to represent in the model and what questions to address. The starting points were information gathered in the facilitator's preliminary interviews with potential participants and the modeller's review of scientific information. The group chose a well-known hydraulic, free-to-use, software package called HEC-RAS. In the second session a basic set-up of the software, representing local river flooding, was introduced to the group. Group members used the software on laptops to draw their own river channel transects and familiarise themselves with the layout. For session three, the modeller had developed a model prototype that was used to explain how different flows could be interpreted as inundation zones, depths and velocities. The fourth session summarised the progress made, including a confirmation of the total volume of flood water calculated as moving through the different channels, and discussing which management options could be effective and feasible. ${ }^{1}$ To conclude the activity, the group created guidance materials enabling the local participants to run scenarios and use the model in their future engagement with flood risk management strategies. The modelling activity was connected to local flood risk management through an Advisory Group, set up by the two project leads in the initial stage of the project (before participants had been recruited), comprising local FRM decision makers.

\footnotetext{
${ }^{1}$ For details about the Community Modelling in Otley, including analysis of flood mitigation options, see Becker et al, 2017.
} 
In the following sections we discuss the participant recruitment, model selection and the connection of the group's work to FRM in Otley in more detail.

\subsection{Recruiting flood affected residents in Otley}

The facilitator led the recruitment of local participants to the group. We sought a maximum of eight participants from the community; with the academics this would make up a group large enough to include a range of different views without preventing constructive and inclusive discussion. The recruitment process was designed to ensure that participants would be able to contribute relevant and varied knowledges and opinions regarding inundation events in the town.

Otley Town Council, a public facing organisation with established interest in local FRM, was instrumental for recruitment within the community. We provided the Council with a recruitment sheet, outlining the project and the expectations on participants. The council suggested thirteen potential participants based upon its records of citizens communicating their concerns about flood management, particularly after the Boxing Day and November 2015 floods. Those suggested were invited to contact the project facilitator if interested. A total of ten members of the community expressed an interest in the project. To increase the potential of group members continuing to be involved after the project, the facilitator invited representatives of the Yorkshire Dales Rivers Trust, a local NGO approaching the issue from an environmental perspective that considers catchment wide processes.

Everybody who had expressed an interest in participating were invited to be interviewed, to gauge their suitability for the CM group and to give them a chance to assess whether they 
wanted to be involved. We held ten interviews, lasting between 20 minutes and one hour, asking prospective participants what their perceptions of flooding in the town were; if they thought computer modelling could contribute to current understandings of flooding in the town; and what they would want the modelling group to achieve. It was crucial to find participants who were sufficiently interested in FRM to attend all meetings and continue to engage with the issues after the project had ended. It was also important that participants were open to discussion and learning about inundation events, not looking only to prove a particular idea. The final group comprised four flood affected residents, a land agent, a former Environment Agency employee, and two Yorkshire Dales Rivers Trust employees.

During the interviews we asked for people's thoughts about the causes and potential solutions to local flooding to form an understanding of how the problem was understood locally. The CM group was later also able to make a call for wider community feedback via Facebook due to one group member also managing the local residents' flood group on the social media site. The suggestions from the community were compiled in a mind-map by the facilitator and used in the first session of the modelling group to prompt discussion and establish the benefits of keeping in contact with interested residents outside of the group.

\subsection{Modelling flooding in a small area with HEC-RAS}

The Community Modelling group in Otley chose to use the hydraulic modelling software HECRAS to address local flooding. HEC-RAS can be used to represent channels in which water flows (such as a river, ditches, and flood flow paths) and to clarify which water volume input conditions cause areas to be inundated, or water to breach its channel. User guides for the model are provided on the download site and the members of the group were encouraged to 
download the software for themselves and to explore it between sessions. The ambition of the group was to be able to run the model and consider the outcomes together. HEC-RAS is complicated to set up and the knowledge and skills of the natural science modeller were critical.

Developed by the US Army Corps of Engineers, HEC-RAS is a computer programme enabling one-dimensional representation of flow in a channel, its variation through time and the spatial extent of inundation associated with that flow. In the simplest of flood simulations, river crosssections defined in the user interface, are simply extended laterally to include the floodplain and the time-dependent flow is applied to the extended sections. In more complex representations the floodplain may be divided into a series of connecting storage cells, with water allowed to flow between them according to water-level heights. In the most complex case the river channel flow is modelled in one-dimension and used as a boundary condition for a two-dimensional treatment using additional software. HEC-RAS was compared to other software programmes for one-dimensional flood modelling in a joint Defra/EA project in the early 2000s (EA, 2005) which approved it for use by technical consultants contracted to provide expert assessments in local flood management in England. It is still widely used for modelling river flooding in small areas and technical experts are familiar with this software, although they use more sophisticated, proprietary software when undertaking commissioned projects.

HEC-RAS is free to use and can be downloaded by anybody, but building a model representation of a local process requires modelling skill and expert knowledge about flooding. The scientific modeller in the Community Modelling group used the Ordnance Survey LiDAR product and topographical survey data of Otley supplied by the EA and Leeds City Council to identify the flow paths in the area prone to flooding. The LiDAR product, made available to 
researchers via Government web sites, provides elevation data in the form of tiles in an orthogonal grid at a spacing defined in the source. For the group's purposes a fine resolution (50 cm) was needed, to capture in sufficient detail the layout of roads, paths, ditches and drains, houses, and so on. To identify smaller structures, such as garden walls, the modeller was able to access a detailed survey of Otley carried out in 2003. The group were provided a full set of pdf format images of this survey for use in the modelling project. The modeller had to make the data usable for HEC-RAS cross-section abstraction and when this was completed, the main flow paths in the area of interest could be identified.

When set up by the scientist the model allowed the group to identify the main flow pathways of the water and establish that the majority of flood waters emanated from the River Wharfe. Running simulations allowed the group to understand the flow volumes, velocities and depths within the modelled area, and reproduce local observations of the Boxing Day 2015 floods (a table with the modelled numbers is reproduced in Figure 3). During the final meeting, the modeller combined the single component models into one lanes-park model, and further developed the river-floodplain model to allow the group to visualise where flood waters spread during peak river flows, and the depths, flow velocities and discharges in different parts of the system. This visualisation and quantification allowed the group to consider various management interventions suggested by the group, the wider community, and the town and city councils. As this was the first time a hydraulic flood modelling has been attempted in detail in the lanes-park area of Otley results had to be treated with caution, but five measures were identified as particularly interesting to investigate further. (i) A new embankment along the river; (ii) opening-up the northern bridge arch; (iii) flood gates at both ends of Back Bridge Avenue; (iv) increasing flow capacity in Kell Beck, Billiams Hill culvert and the moat and (v) reducing the height of the weir. 
The Community Modelling impacted on the understanding of flooding amongst the local participants. In the beginning of the project they described flooding as 'large' or 'rapid' or 'deep', at the end they were able to relate these qualitative terms to quantities, thus demonstrating understanding of how flooding is expressed by numbers. The local participants also became able to run scenarios and discuss the outputs with support of the co-produced tutorials (see screenshot in Figure 4 for an example). The ability to understand the quantitative descriptions of local flooding in the model increased the local participants' capacity to communicate with decision makers.

\subsection{Connecting the modelling group with ongoing FRM projects}

That the initiative to the Otley Community Modelling project came from a local town councillor provided a link to decision making bodies from the outset. In an early visit with involved town council members the project leads had learned about the wider decision making context, and about the relationships between residents affected by flooding and the authorities on the regional level.

Before the start of the CM activity a meeting was arranged with Otley Town councillors, flood risk managers from Leeds City Council (the statutory authority of FRM in Otley) EA, technical consultants and the academic project team. This meeting decided to form an Advisory Group that would receive regular updates on the progress of the modelling group and to hold another meeting at the end of the project. 
Another, spontaneous, connection to flood risk management in the area occurred when the natural scientist leading the group's modelling made contact with the technical consultant leading Leeds City Council's work when taking inventory of previous modelling and data sources. He was invited to a meeting held to develop a shared understanding of the different flood modelling projects going on in the catchment. The project was presented at the meeting and there was agreement about exchanging information between the local group in Otley and the Middle Wharfe modelling study.

Throughout the project the social science group facilitator provided the Advisory Group members with progress updates after each modelling session, and after the fourth session the local participants in the group were invited to a meeting. At this meeting the local CM participants explained what they had done and their modelled findings. Importantly, the meeting discussed how to keep the local residents involved in the wider flood management process in the area.

\section{Concluding discussion}

While scientific PM projects have had demonstrated success with integrating scientific and local knowledge in models they have had limited uptake in institutional decision making. Studies have shown that the scientific framing of PM promotes the production of new knowledge and new computer programmes, but that these are not necessarily useful to decision makers. Informed by political goals and policy requirements, environmental, including flood risk, managers are often more interested in local participation as such, rather than the products generated by public participation in scientific modelling. 
Having established that a significant challenge for scientific PM is to create ongoing community engagement with flood risk (and other environmental) managers we introduced the Community Modelling technique. The overall aim of this approach is to enhance the capacity of local publics to participate in FRM and other environmental risk management processes, after the completion of the scientific modelling activity.

We outlined CM in general, as applicable to all local environmental management issues in which computer simulation modelling plays a role. The presentation highlighted four core elements: resource minimalism, strategic participant recruitment, standardised software and actively connecting with decision makers. Led by two academics, a social science facilitator and a natural science modeller, CM gathers a small group that work together over a three to four month period. This brings down the cost and the time local participants need to set aside. Selecting local participants with regard to their potential to continue to engage in the longterm, in addition to their interests and local knowledge, speaks to the aim of capacity building. Working with free-to-use software in three to four workshop sessions CM opens up the modelling process to lay participants who learn about how to set up, run and check a computer model representing the issue that is a matter of concern to them. The academics also actively connect the local participants in the modelling group with decision makers on the relevant geographical scale.

The CM format was applied in a case study of flood risk management in an English town. The case study allowed elaboration on the four core elements. The first, resource minimalism, was tested by applying a strict time frame. The limited time commitment needed was appreciated by the local participants, who had many other things to do, but were able to commit to four evening meetings over a period of four months. In all, the two academic staff used 150 
workdays, including preparations and follow-up work. The strategic recruitment of local participants achieved the objective of creating a small research group with a wide range of ideas and experiences. The local participants were also actively communicating about the work in the group to the wider local community. The use of the off-the-shelf modelling software HEC-RAS to represent local flood process and consider possible risk reduction options enabled the group to analyse the problem in depth. Using the software on this small scale was challenging and the need to engage natural science modellers with a high level of expertise was highlighted. Finally, the active connection of the group’s work with flood risk management projects and decision making in the area was effective.

Beyond demonstrating the value of the Community Modelling technique for involving a local people with FRM the Otley case study also showed the value of computer models for facilitating communication. In the second Advisory Group meeting with local participants from the modelling group it became clear that the modelling activity had provided the local residents with a vocabulary with which they could communicate with the flood risk managers and the technical experts. Using the HEC-RAS software package to represent locally observed and measured flooding processes gave the lay participants access to a coherent way of communicating about their own risk of being flooded. The preliminary interviews had generated a plethora of different ideas about why and how flooding occurred in Otley and what to do about it. Every interviewee had their own, not necessarily internally consistent, ideas. Working together, using the modelling software to structure the exploration of local flooding, created shared understanding of how the local environmental process worked and which possible interventions it would be worthwhile to investigate further. Working with the model supported their construction of coherent arguments that could be presented to decision makers. Using the HEC-RAS model of the local flooding process as a point of reference the local 
participants found it easier to communicate with the technical experts. A local participant has told us that the CM had 'been invaluable as a means of giving us a better footing in discussions with the [Leeds City FRM] project team' (personal communication 07.08.2018). That the CM activity would facilitate the articulation of local knowledge through deliberation in the group was expected, but the role of the model in providing a vocabulary and supporting communication with experts after such a short time was a surprise.

The active promotion of continued community participation in local environmental risk management sets the Community Modelling technique apart from other PM approaches. The CM project in Otley was successful in opening pathways for the local community to interact with decision making organisations. According to the same local CM participant as quoted above 'A lot of the options that were considered [by the Leeds City FRM project] came from the group work and were shown to have varying effectiveness on the flood levels' (personal communication 07.08.2018). Further research is needed to establish to what extent the local participants continue to engage with the FRM programme for the Wharfe catchment in coming years. Further research is also needed to improve understanding of what kind of support local communities need to remain involved with the knowledge production in environmental management processes in the long-term.

\section{References}

Becker, M., Odoni, N., Landström, C., Whatmore S. J., 2017 Community Modelling: Incorporating local knowledge into hydraulic flood modelling in Otley, Yorkshire (downloadable from www.communitymodelling.org). 
Becu, N., Neef, A., Schreinemachers, P., Sangkapitux, C., 2008. Participatory computer simulation to support collective decision-making: Potential and limits of stakeholder involvement. Land Use Policy 25, 498-509.

Evers, M., 2012. Participation in Flood risk Management An introduction and recommendations for implementation. Centrum för klimat och säkerhet Rapport 2012:1

Evers, M., Jonoski, A., Almoradie, A., Lange, L., 2016. Collaborative decision making in sustainable flood risk management: A socio-technical approach and tools for participatory governance. Environmental Science \& Policy 55, 335-344.

EA (Environment Agency), 2005. Benchmarking of hydraulic river modelling software packages Project Overview, R\&D Technical Report: W5-105/TR0 Defra/Environment Agency Flood and Coastal Defence R\&D Programme. Bristol: Environment Agency.

European Union, 2007. October 23. Directive 2007/60/EC of the European Parliament and the Council on the assessment and management of flood risks. Official Journal of the European Union, L 288/27-L 288/34.

Hare, M., 2011. Forms of Participatory Modelling and its Potential for Widespread Adoption in the Water Sector. Environmental Policy and Governance 21, 386-402.

Henly-Shepard, S., Gray, S. A., Cox, L. J., 2015. The use of participatory modelling to promote social learning and facilitate community disaster planning. Environmental Science \& Policy 45, 109-122. 
Lane, S. N., Landström, C., Whatmore, S., 2011. Imagining flood futures: risk assessment and management in practice. Philosophical Transactions of the Royal Society A 369, 1784-1806.

Maskrey, S. A., Mount, N. J., Thorne, C. R., Dryden, I., 2016. Participatory modelling for stakeholder involvement in the development of flood risk management intervention options. Environmental Modelling and Software 82, 275-294.

Maynard, C. M., 2013. How public participation in river management improvements is affected by scale. Area 45, 230-238.

Newig, J., Challies, E., Jager, N., Kochskämper, E., 2014. What Role for Public Participation in Implementing the EU Floods Directive? A Comparison With the Water Framework Directive, Early Evidence from Germany and a Research Agenda. Environmental Policy and Governance 24, 275-288.

Petts, J., Brooks, C., 2006. Expert conceptualisations of the role of lay knowledge in environmental decision making: Challenges for deliberative democracy. Environment and Planning A 38, 1045-1059.

Reed, M. S., 2008. Stakeholder participation for environmental management: A literature review. Ecological Conservation 141, 2417-2431. 
Smith, R., Kaspryrzyk, J., Dilling, L., 2017. Participatory Framework for Assessment and Improvement of Tools (ParFAIT): Increasing the impact and relevance of water management decision support research. Environmental Modelling \& Software 95, 432-446.

Thalers, T., Levin-Keitel, M., 2016. Multi-level stakeholder engagement in flood risk management - A question of roles and power: Lessons from England. Environmental Science \& Policy 55, 292-301.

Van Ast, J. A., Gerrits, L., 2017. Public participation, experts and expert knowledge in water management in the Netherlands. Water Policy 19, 115-127.

Van der Wal, M.M., de Kraker, J., Kroeze, C., Kirschner, P. A., Valkering, P., 2016. Can computer models be used for social learning? A serious game in water management. Environmental Modelling \& Software 75, 119-132.

Voinov, A., Bousquet, F., 2010. Modelling with stakeholders. Environmental Modelling \& Software 25, 1268-1281.

Voinov, A., Kolagani, N., McCall, M. K., Glynn, P. D., Kragt, M. E., Ostermann, F. O., Pierce, S. A., Ramu, P., 2016. Modelling with stakeholders - Next generation. Environmental Modelling \& Software 77, 196-220.

Webler, T., Tuler, S., Dietz, T., 2011. Modellers’ and Outreach Professionals’ Views on the Role of Models in Watershed Management. Environmental Policy and Governance 21, 472486. 
Whatmore, S. J., 2009. Mapping knowledge controversies: science, democracy and the redistribution of expertise. Progress in Human Geography 33, 587-598.

Whatmore, S. J., Landström, C., 2011. Flood-Apprentices: An Exercise in Making Things Public. Economy \& Society 40, 582-610.

Whitman, G. P., Pain, R., Milledge, D. G., 2015. Going with the flow? Using participatory action research in physical geography. Progress in Physical Geography 39, 622-639. 
Figure 1: Community Modelling project in Otley

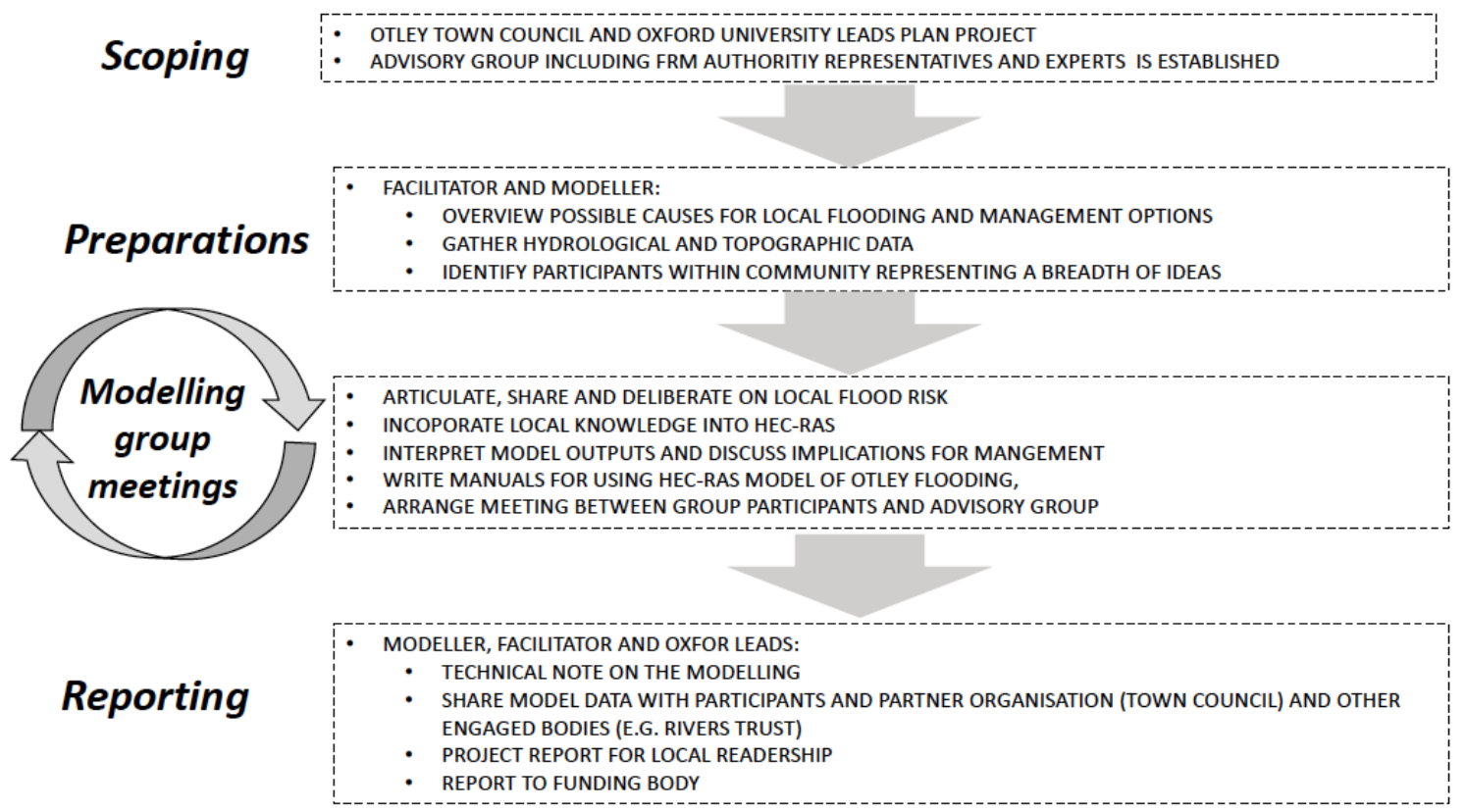

Figure 2: The four modelling group meetings in Otley

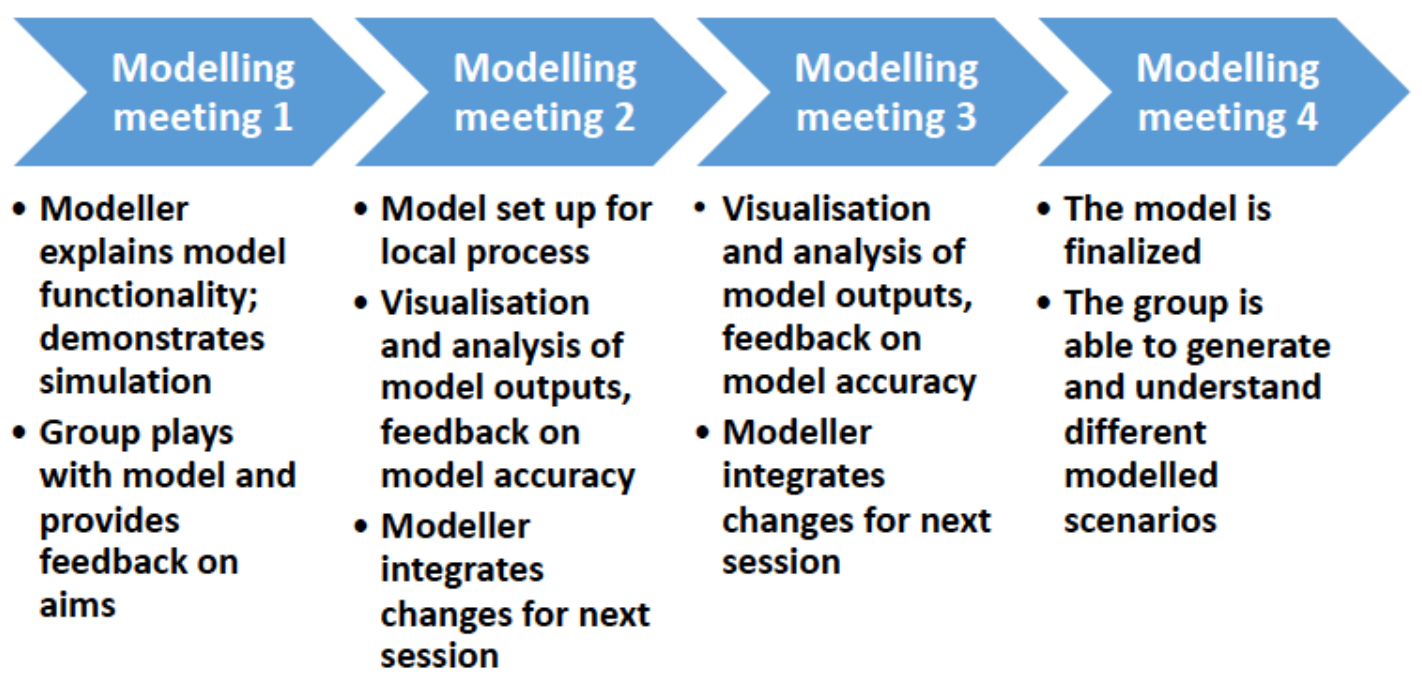


Figure 3: Table from Becker et al., 2017.

Table 2: Plausible mid-values selected from a range of model simulations with the HEC-RAS lanespark model, quantifying the conditions at the peak of the flood on Boxing Day, 2015.

\begin{tabular}{|c|c|c|c|}
\hline & $\begin{array}{l}\text { Modelled peak } \\
\text { flow discharge } \\
\left(\mathrm{m}^{3} \cdot \mathrm{s}^{-1} \text {, or }\right. \\
\text { 'cumecs') }\end{array}$ & $\begin{array}{l}\text { Mean flow velocity } \\
\text { at peak discharge } \\
\left(\mathrm{m} \cdot \mathrm{s}^{-1}\right)\end{array}$ & $\begin{array}{l}\text { Mean flood depth } \\
\text { ('stage') at peak } \\
\text { discharge (m) }\end{array}$ \\
\hline Farnley Lane & 6.0 & 0.7 & 0.9 \\
\hline $\begin{array}{l}\text { Back Bridge } \\
\text { Avenue }\end{array}$ & 4.2 & 0.8 & 1.0 \\
\hline $\begin{array}{l}\text { Moat, main open } \\
\text { channel section only }\end{array}$ & 0.8 & 0.3 & 0.9 \\
\hline
\end{tabular}

Figure 4: Screenshot from tutorial co-produced by Otley CM group.

In the geometric data viewer click on the "Bridg/Culv." button on the left ( $3^{\text {rd }}$ down). You can see the bridge looking at it from upstream, and the perspective from being on the bridge and looking downstream. The tops of the arches are drawn $1.5 \mathrm{~m}$ below the top of the bridge. Close this window.

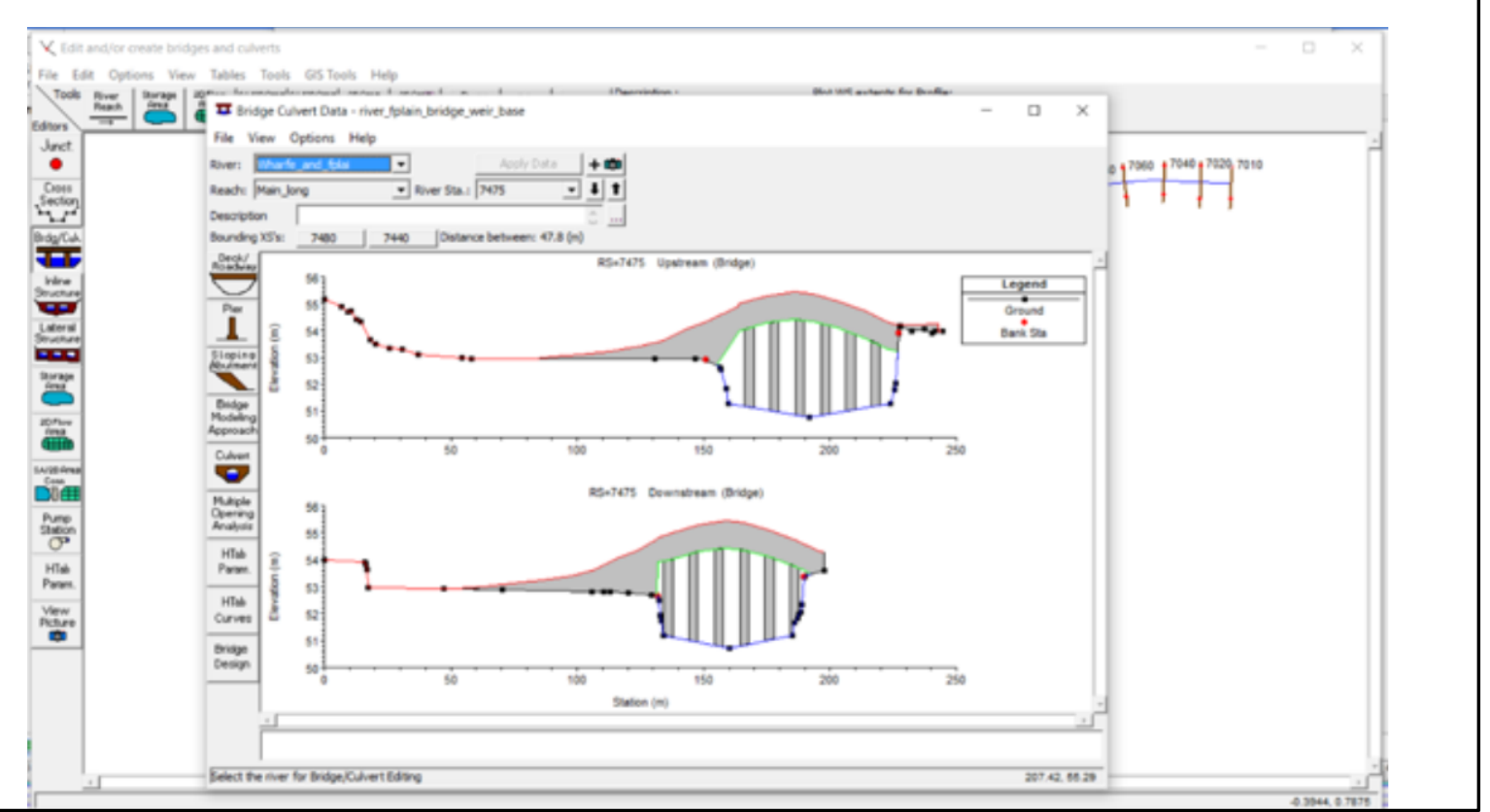

